\title{
ANNOUNCEMENTS
}

The 2nd International Conference of

THE HOSPITAL INFECTION SOCIETY

will be held in LONDON on September 2nd-6th, 1990

In 1987, when the 1st International Conference was held, over 1000 delegates attended the event which proved to be remarkably successful. Their primary activities were related to hospital infection, its management and prevention.

The 2nd International Conference will be attended by physicians, medical microbiologists, research scientists and hospital infection control personnel from many parts of the world. The scientific programme will address the current interests and concerns in the field of microbial disease, and will comprise symposia, workshops, free communications and posters.

In addition to the scientific programme mentioned above, the Conference will be supplemented by a major trade exhibition which will afford exhibiting companies a unique opportunity to address this market sector.

Further information and a copy of the registration form may be obtained from the Conference Secretariat:

Conference Associates HIS, Congress House,

55 New Cavendish Street, London W1M 7RE, United Kingdom.

Telephone 014860531 , Telefax 019357559.

\section{PATHOLOGICAL SOCIETY FELLOWSHIP}

The Pathological Society of Great Britain and Ireland is sponsoring a small number of Fellowships to members of the medical and scientific professions working in UK or Ireland in experimental and/or pathologically or microbiologically-related medical research to visit other institutions for periods up to 12 months to learn new investigative techniques. Preference will be given to those requiring additional funds to augment existing salary. Further details and application forms from Professor R. B. Goudie, Department of Pathology, Royal Infirmary, Glasgow G4 0SF. 